Original Article

\title{
Stress and Coping Status among Caregivers of Major Psychiatric Patients
}

\author{
Tasmin $S,{ }^{1}$ Sultana $\mathrm{H},{ }^{2}$ Haque $A,{ }^{3}$ Islam MM,${ }^{4}$ Alam MR ${ }^{5}$, Halim $\mathrm{KS}^{6}$, *Abbas $\mathrm{MG}^{7}$
}

\begin{abstract}
Caregivers play an important role for the treatment and wellbeing of the psychiatric patients. Constant caregiving role exert stress on the caregiver which is usually handled by them. This cross-sectional study aimed to assess the level of stress and coping status among conveniently selected 171 care givers of major psychiatric patients at National Institute of Mental Health (NIMH), Dhaka. Data was collected by the pre-tested semi-structure questionnaire blended with perceived stress and coping scale through face to face interview. Average coping status was found in most of the (70\%) care givers; good coping status was found in more than one fifth (21\%) of the caregivers and few (02\%) caregivers had poor coping status. Stress and coping status was found $(p<0.05)$ significantly related. This study finds the perceived stress among all the caregivers under study population; where high level of stress were perceived by more than three fourth of the caregivers and moderate to low level of stress were perceived by most of the caregivers. Caregiver-centric interventions, services and programs are recommended to plan and implement so that they should not compromise their caregiving work.
\end{abstract}

Keywords: Stress, coping status, caregiver, psychiatric patient.

1. Dr. Sinthia Tasmin, Lecturer, Institute of Public Health, Mohakhali, Dhaka.

2. Dr. Hafiza Sultana, Professor and Head, Department of Health Education, National Institute of Preventive and Social Medicine (NIPSOM), Mohakhali, Dhaka.

3. Dr. Aysha Haque, Lecturer, Department of Health Education, NIPSOM, Mohakhali, Dhaka

4. Dr. Md. Moinul Islam, Resident Surgeon, Department of Neurosurgery, Dhaka Medical College (DMC)

5. Dr. Mohammad Rashidul Alam, Assistant Professor (Community Medicine), Department of Health Education, NIPSOM, Mohakhali, Dhaka

6. Prof. Dr. Kazi Shafiqul Halim, Professor and Head, Department of Epidemiology, NIPSOM, Mohakhali, Dhaka

7. *Dr. Md. Golam Abbas PhD, Assistant Professor, Department of Occupational and Environmental Health (OEH), NIPSOM, Mohakhali, Dhaka. Email: abbasgolam@yahoo.com

${ }^{*}$ Corresponding author

\section{INTRODUCTION}

Mental disorder accounts for $13 \%$ global burden of disease. ${ }^{1}$ About 1 in 17 people worldwide suffers from a serious mental illness. ${ }^{2}$ Depression, psychosis, schizophrenia and bipolar disorder are the four out of six leading causes for the years lived with disability. ${ }^{3}$ According to the World Health Organization (WHO), mental illness is found in at least one member of any one of the four families which results in family members providing care towards their sick member as a primary caregiver. ${ }^{3}$ Although there is no valid data about the number of people suffering from the major psychiatric condition, the prevalence of mental disorder is varied from $6.5 \%$ to $31 \%$ and $13.4 \%$ to $22.9 \%$ respectively among adults and children in Bangladesh ${ }^{1}$ Bangladesh has been trying to provide institutionalized based health-care services to the mentally ill population since its independence. Of these, establishment of National Institute of Mental Health (NIMH) in 2000, and adoption of a mental health policy, strategy and plan in 2006 is significant. Although it was well known that appropriate medication is the principal element for optimizing a patient's function, it is also the case that the quality of care provided by family caregivers is important. ${ }^{4}$

A family caregiver may be a family member, a parent, a spouse, a son, a daughter, or other relatives or friends. ${ }^{5}$ The caregiver not only stays with the patients but also allocates time to take proper care of them. ${ }^{6}$ Uninterrupted caregiving can cause caregivers to create stress or strain, and lower levels of physical and mental well-being, and limit the caregivers' ability to perform their caregiving tasks. It is evident that moderate to severe stress is developed among caregivers of psychiatric patients. ${ }^{2}$ Consequently, stress can lead to deterioration of physical and mental health. Mant et al (2005) state that caregivers are at high risk in developing physical and mental illness because of having excessive depression and stress resulting from performing psychiatric patients' daily activities. ${ }^{7}$ Prior studies have shown that the development of depression among caregivers is a very common mental illness. ${ }^{8,9}$ In addition to this, anxiety and stress symptoms are also experienced by the caregivers. ${ }^{10}$ Lack of motivation, less or nil financial support and social isolation have been described as the most problematic area for caregivers. ${ }^{11}$ Because of the deficiency of social, psychological and financial support, the quality of life of caregivers can be negatively affected; as a result, their effectiveness as caregivers is disrupted which can result in deterioration of the health of the sick family member. 
Coping is understood as the process of managing demands (external or internal) that are appraised as taxing or exceeding the resources of the person which is seen as a process involving at least two stages: Primary appraisal (is this something to bother about?), and secondary appraisal (what can I do about it?). ${ }^{12}$ It is proposed to serve two distinct purposes: To do away with the problem (i.e., problem-focused coping), and to regulate emotional reactions (emotion-focused coping). ${ }^{13}$ Previous studies have not used the same assessment scale to identify coping strategies; as a result, it is difficult to compare their results with each other. A study using family coping questions found that more than half of caregivers adopted information, positive communication, patient social involvement, and resignation as their coping strategies. ${ }^{14}$ Social involvement of the patient and positive communication as coping strategies were most frequently reported by both key relatives and other relatives in another study based on the family coping questionnaire. ${ }^{15}$ On the other hand, a study used a combination of three coping frameworks namely cognitive or behavioral, social or non-social, problem-centered or emotion-centered suggesting that relatives often use behavioral coping responses more than cognitive, more socially than non-social and more emotionally than problem-focused coping strategy. ${ }^{16}$ Other studies have reported most frequent use of problem focused coping. ${ }^{17}$ self-controlling, positive reappraisal and escape-avoidance coping. ${ }^{18}$ In Bangladesh, no studies have been conducted so far in regards to the coping status and strategies among the caregivers of psychiatric patients.

Caregivers play a significant role in the treatment and wellbeing of the patient. When caregivers suffer from stress, it may be difficult for the patient to recover from illness. If the caregivers are not being able to cope with the stress, the situation becomes complicated. In our country almost, all psychiatric illness patients depend on the care provided by their family members. Every patient needs a compulsory all-time caregiver from their family during his or her hospital stay especially in public hospitals. This study has aimed to provide policy makers and healthcare providers with some essential information that will help planning programs and services to alleviate the suffering of caregivers and build support for them that will ultimately contribute to the recovery of mental patients.

\section{MATERIALS AND METHODS}

This cross-sectional study was conducted among the caregivers of major psychiatric patients of National Institute of Mental Health (NIMH), Dhaka lasting from $1^{\text {st }}$ of January to $31^{\text {st }}$ of December, 2019. The inclusion criteria for psychiatric patients was the duration of disorder $>=6$ months. Caregivers whose age was $>=18$ years, and who spent at least 30 minutes a day and $\geq 2$ months with a psychiatric patient were included in the study. On the other hand, smokers, diabetic, psychiatric and physically ill, and unwilling caregivers were excluded from the study. In order to select the sample size of the study, a standard equation was used.${ }^{19} \mathrm{Al}$ though a total of 179 caregivers were scheduled to be interviewed, 171 were set as the final number due to the reluctance of caregivers to participate in the study. Data were collected through a semi-structured questionnaire blended with perceived stress and coping scale. This questionnaire contained four parts such as socio-demographic status of caregivers, caregiving and care recipient related questions, caregiver's stress and coping information. Caregiver stress related question by using perceived stress scale PSS 10 version scale used. PSS Scale 10 version comprises 10 Question. Here cut off point is $0=$ never,

$1=$ almost never, $2=$ sometimes, $3=$ Fairly often, $4=$ very often Here $0-13=$ Low stress, $14-26=$ moderate stress, $27-40=$ High perceived stress. Caregiving coping related question by using coping scale. Coping scale 13 question. Each answer category was assigned a value from 4 to 1 . The total score can be a sum or mean of all items .we used Z-score of the in our analyses. Higher score indicates higher levels of coping. Here $4=$ Mostly true about me, $3=$ somewhat true about me, $2=\mathrm{A}$ little true about me, $1=$ Not true about me. Score $13-25$ poor coping, 26-38 average, 39-52 good coping. Prior to the implementation of questionnaire, a pretest was carried out at the Dhaka Medical College to check the validity and credibility of the questionnaire. A face to face interview was taken from the caregivers of mentally sick patients at the ward or cabin of $\mathrm{NIMH}$ after the final modification of the questionnaires. After receiving written consent from the caregivers, the interview proceeded. The data were checked for consistency and completeness and inserted, cleaned and recorded in the SPSS version 20 before moving to analysis. Descriptive statistics of frequency, percentage, means, medians, mode, standard deviation, tables and graphs were used to summarize the data. Chi-square $(\chi 2)$ test was used to explore the association and correlation between variables. A P-value of $<0.05$ was considered as significant. Before commencing the study, the necessary approval was taken from the ethical committee of the National Institute of Preventive and Social Medicine (NIPSOM). Further, permission was also sought from the authority of the NIMH before implementing the interview towards the caregivers of major psychiatric patients.

\section{RESULTS}

Table I Shows illustrates the socio-demographic status of the caregiver. Among them, $90.6 \%$ caregivers mentioned their religion as Islam. $28.7 \%$ of caregivers were over 47 years, representing the higher age group of caregivers among other age groups. The Mean \pm SD of caregivers' age was $40.09( \pm 13.31)$ years. Among the caregivers, the percentage of female and male was $74 \%$ and $26 \%$ respectively. About 
$33 \%$ of caregivers identified them as illiterate, while only $4 \%$ caregivers had a master's degree. $57.9 \%$ of participants cited housewives as their occupation which was the highest among other occupations of caregivers. At the time of the interview, 77.2 percent of the participants were married and $65 \%$ were living as a nuclear family. Further, $43.9 \%$ of caregivers monthly family income was $<=10,000$.

Table I: Socio-demographic status of caregiver $(n=171)$

\begin{tabular}{|c|c|c|}
\hline & Variables & Percentage (\%) \\
\hline \multirow{4}{*}{$\begin{array}{l}\text { Age group } \\
\text { (in years) }\end{array}$} & $18-27$ & 19.3 \\
\hline & $28-37$ & 24.6 \\
\hline & $38-47$ & 27.5 \\
\hline & $>47$ & 28.7 \\
\hline & \multicolumn{2}{|c|}{$40.09( \pm 13.31)$ years } \\
\hline \multirow[t]{2}{*}{ Gender } & Male & 26 \\
\hline & Female & 74 \\
\hline \multirow{6}{*}{$\begin{array}{l}\text { Educational } \\
\text { status }\end{array}$} & Illiterate & 33 \\
\hline & Primary & 22 \\
\hline & Secondary & 24 \\
\hline & Higher Secondary & 8 \\
\hline & Honor's & 9 \\
\hline & Master's & 4 \\
\hline \multirow[t]{6}{*}{ Occupation } & Housewife & 57.9 \\
\hline & Service holder & 18.7 \\
\hline & Business & 6.4 \\
\hline & Farmer & 5.3 \\
\hline & Student & 5.3 \\
\hline & others & 6.4 \\
\hline \multirow[t]{4}{*}{ Marital Status } & Unmarried & 14.6 \\
\hline & Married & 77.2 \\
\hline & \begin{tabular}{|l} 
Separated \\
\end{tabular} & 1.2 \\
\hline & Widow/Widower & 7.0 \\
\hline \multirow[t]{2}{*}{ Family type } & Nuclear & 65 \\
\hline & Joint & 35 \\
\hline \multirow[t]{4}{*}{ Family Income } & $<=10,000$ & 43.9 \\
\hline & $10,001-20,000$ & 32.2 \\
\hline & 20,001-30,000 & 14 \\
\hline & $>30,001$ & 9.9 \\
\hline \multirow{6}{*}{$\begin{array}{l}\text { Relationship } \\
\text { with the patients }\end{array}$} & Husband/wife & 18.7 \\
\hline & Son/daughter & 49.7 \\
\hline & Son/daughter in law & 2.9 \\
\hline & Siblings & 19.9 \\
\hline & Brother/sister in law & 3.5 \\
\hline & Other & 5.3 \\
\hline \multirow[t]{2}{*}{ Religious status } & Muslim & 90.6 \\
\hline & Hindu & 9.4 \\
\hline
\end{tabular}

Table II: Shows it is noticed that complete independence with no longer was identified by the participants of $53.8 \%$ in eating, $48.5 \%$ in daily activities and $64.3 \%$ in bowel/bladder, while at eating $4.7 \%$, at daily activities $4.7 \%$ and at bowel/bladder management $5.3 \%$ of respondents had required minimal assistance with helper.

\section{Table II : Activities related to caregiver and care recipients}

\begin{tabular}{|l|c|}
\hline $\begin{array}{l}\text { Activities related to caregiver } \\
\text { and care recipients }\end{array}$ & Percentage \\
\hline Eating & 7.0 \\
\hline Total assistance with helper & 9.4 \\
\hline Moderate assistance with helper & 4.7 \\
\hline Minimal assistance with helper & 25.1 \\
\hline Supervision with helper & 53.8 \\
\hline Complete independence with no longer & \\
\hline Daily activities & 6.4 \\
\hline Total assistance with helper & 9.4 \\
\hline Moderate assistance with helper & 4.7 \\
\hline Minimal assistance with helper & 31.0 \\
\hline Supervision with helper & 48.5 \\
\hline Complete independence with no longer & \\
\hline Bowel/bladder management & 3.5 \\
\hline Total assistance with helper & 6.4 \\
\hline Moderate assistance with helper & 5.3 \\
\hline Minimal assistance with helper & 20.5 \\
\hline Supervision with helper & 64.3 \\
\hline Complete independence with no longer & \\
\hline
\end{tabular}

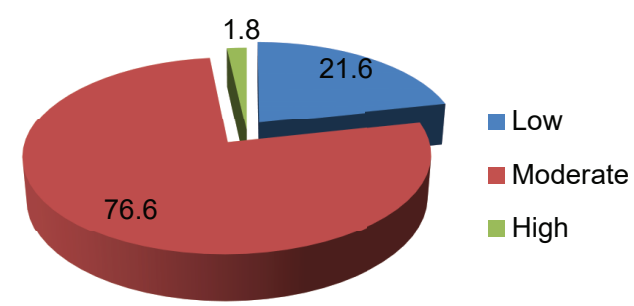

Figure 1 : Stress percentage of different levels considered by the caregiver $(\mathrm{n}=171)$

Figure 1 illustrates the stress percentage of different levels considered by the caregiver. It is seen that low, moderate, and high levels of stress were perceived by $21.6 \%, 76.6 \%$, and $1.8 \%$ of caregivers respectively. 
Table III: Shows the caregivers previously employed were $20(11.7 \%)$, had to leave the job $13(7.6 \%) \&$ took financial support 5 (2.9\%). Mean duration of caregiving (months) 45.76 months $( \pm$ SD 59.38) \& Mean caregiving time was (hours/day) 18.56 ( \pm SD 8.07).

\section{Table III: Distribution of caregiver their caregiving related information $(n=171)$}

\begin{tabular}{|l|c|c|}
\hline Attributes & Frequency & Percentage \\
\hline Caregiver employed previously & 20 & 11.7 \\
\hline Caregiver had to leave the job & 13 & 7.6 \\
\hline Financial support & 5 & 2.9 \\
\hline Caregiving duration (months) & \multicolumn{2}{|c|}{$45.76 \pm 59.38$} \\
\hline Caregiving time (hours/day) & \multicolumn{2}{|c|}{$18.56 \pm 8.07$} \\
\hline
\end{tabular}

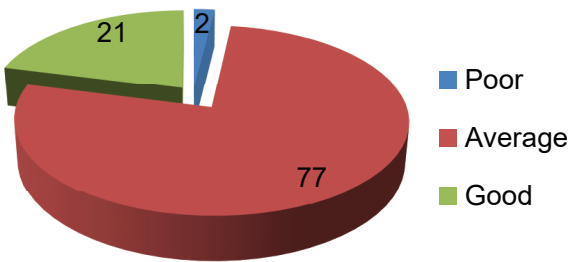

Figure 2 : Percentage of caregivers coping status

The pie chart above presents the status of the caregiver in terms of coping as a percentage (Figure 2). Most of the participants' $(77 \%)$ coping status was average followed by good $(21 \%)$ and poor $(2 \%)$.

Table IV: Shows the p-value for age was (0.241) followed by the marital status $(0.241)$, educational status $(0.122)$ and income level (0.044). Since income level's p-value was less than 0.05 , representing it is as statistically significant. Therefore, income level has an association with the stress.

Table IV: Association between socio-demographic status and perceived stress of caregiver $(\mathbf{n}=171)$

\begin{tabular}{|c|c|c|c|c|c|}
\hline Variables & Low stress & Moderate Stress & High stress & $\chi 2$ Value & P-value \\
\hline Age groups (years) & $\mathrm{N}(\%)$ & $\mathrm{N}(\%)$ & $\mathrm{N}(\%)$ & & \\
\hline $18-27$ & $6(16.2)$ & $25(19.1)$ & $2(66.7)$ & & \\
\hline $28-37$ & $8(21.6)$ & $33(25.2)$ & $1(33.3)$ & 6.907 & 0.241 \\
\hline $38-47$ & $8(21.6)$ & $39(29.8)$ & $0(0.0)$ & & \\
\hline$>47$ & $15(40.6)$ & $34(26.0)$ & $0(0.0)$ & & \\
\hline \multicolumn{6}{|l|}{ Educational status } \\
\hline Illiterate & $9(24.3)$ & $49(37.4)$ & $0(0.0)$ & & \\
\hline Primary & $8(21.6)$ & 27 (20.6) & $0(0.0)$ & & \\
\hline SSC & $7(18.9)$ & $28(21.4)$ & $1(33.3)$ & 13.2 & 0.122 \\
\hline HSC & $4(10.8)$ & $11(8.4)$ & $1(33.3)$ & & \\
\hline Graduation & $5(13.5)$ & $12(9.2)$ & $0(0.0)$ & & \\
\hline Post graduation & $4(10.8)$ & $4(3.1)$ & $1(33.3)$ & & \\
\hline \multicolumn{6}{|c|}{ Monthly Income (BDT) } \\
\hline$<10,000$ & $14(37.8)$ & $61(46.6)$ & $0(0.0)$ & & \\
\hline $10,001-20,000$ & $10(27.0)$ & $44(33.6)$ & $1(33.3)$ & 10.685 & 0.044 \\
\hline $20,001-30,000$ & $8(21.6)$ & $16(12.2)$ & $0(0.0)$ & & \\
\hline$>30,000$ & $5(13.5)$ & $10(7.6)$ & $2(66.6)$ & & \\
\hline
\end{tabular}


Table $\mathrm{V}$ shows the association between socio-demographic and coping status. The p-value for educational status, profession, income level, and type of family was $0.235,0.070$, and 0.085 respectively. As none of the variables' p-value was lower than 0.05 , therefore, there is no association between these with the coping status.

Table V: Association between socio-demographic and coping status $(n=171)$

\begin{tabular}{|l|c|c|c|c|c|}
\hline Variables & Poor Coping & Average Coping & Good Coping & X2 Value & P-value \\
\hline Educational status & $\mathrm{N}(\%)$ & $\mathrm{N}(\%)$ & $\mathrm{N}(\%)$ & & \\
\hline Illiterate & $1(50.0)$ & $45(33.3)$ & $12(35.3)$ & & \\
\hline Primary & $0(0.0)$ & $28(20.7)$ & $7(20.6)$ & & \\
\hline SSC & $0(0.0)$ & $25(18.5)$ & $11(32.4)$ & $11.57^{*}$ & 0.235 \\
\hline HSC & $0(0.0)$ & $15(11.1)$ & $1(2.9)$ & & \\
\hline Graduation & $0(0.0)$ & $14(10.4)$ & $3(8.8)$ & & \\
\hline Post graduation & $1(50.0)$ & $8(5.9)$ & $0(0.0)$ & & \\
\hline Monthly Income (BDT) & & & & \\
\hline$<10,000$ & $0(0.0)$ & $60(44.4)$ & $15(44.1)$ & 9.996 & 0.070 \\
\hline $10,001-20,000$ & $0(0.0)$ & $43(31.9)$ & $12(35.3)$ & & \\
\hline $20,001-30,000$ & $0(0.0)$ & $18(13.3)$ & $6(17.6)$ & & \\
\hline$>30,000$ & $2(100.0)$ & $14(10.4)$ & $1(2.9)$ & & \\
\hline Family Type & $2(100.0)$ & $91(67.4)$ & $18(52.9)$ & 3.174 & 0.085 \\
\hline Nuclear & $0(0.0)$ & $44(32.6)$ & $16(47.1)$ & & \\
\hline Joint & & & & \\
\hline
\end{tabular}

Table Vl shows 50\% ( $\mathrm{n}=1$ ) had poor coping, $23.7 \%$ (32) had average coping and 11.8\% (4) had good coping status among the respondents having low stress. In contrast, $0.0 \%(0), 74.8 \%(101)$ and $88.2 \%(30)$ moderately stressed respondents had represented poor; average and good coping status respectively. Respondents having high perceived stress had 50\% (1) poor coping, $1.5 \%(2)$ had average coping and $0.0 \%(0)$ had good coping status. This difference was statistically significant ( $\mathrm{p}$ value: 0.009 ). So there was an association between level of stress and coping status

Table Vl: Relationship between stress and coping status $(\mathrm{n}=171)$

\begin{tabular}{|l|c|c|c|c|c|}
\hline \multirow{2}{*}{ Stress Level } & \multicolumn{3}{|c|}{ Coping } & \multirow{2}{*}{$\chi^{2}$ Value } & p-value \\
\cline { 2 - 5 } & Poor & Average & Good & & \\
\hline Low stress & $1(50.0)$ & $32(23.7)$ & $4(11.8)$ & 12.669 & $0.009^{*}$ \\
\hline Moderate stress & $0(0.0)$ & $101(74.8)$ & $30(88.2)$ & & \\
\hline High perceived stress & $1(50.0)$ & $2(1.5)$ & $0(0.0)$ & & \\
\hline
\end{tabular}




\section{DISCUSSION}

Current study found that $49(28.7 \%)$ of caregivers aged over 47 years followed by $47(27.5 \%), 42(24.6 \%)$, and 33 (19.3\%) within the age group 38-47years, 28-37 years, and $18-27$ years respectively. Unlike this finding, $45.9 \%$ of participants were between 18-30 years of age group, and $30.6 \%$ and $13.8 \%$ were between $31-40$ years and $41-50$ years age group respectively in a study conducted by Karim et al (2011).$^{20}$ Differences in the results of the two studies have been observed due to the different criteria of inclusion for the study and the lack of a universal scale for age-based group selection. Therefore, it is important to introduce a standard scale for selecting the participants based on the age-based group.

To classify gender-based caregivers, one piece of research proves that there were more women than men as caregivers. ${ }^{21}$ which support the current study. As a result, women are more at risk of developing mental illness than men. In addition, the study reveals the normal state of culture in Bangladesh, especially marital and religious status, as most caregivers expressed themselves as Muslims $(90.6 \%)$ and married (77.2 \%). Further, this study also presents that parental bonding is stronger in Bangladesh like other studies ${ }^{22}$ since $49.7 \%$ of caregivers were found as the parents of the patients. Despite this study being carried out in a tertiary hospital situated in the capital of Bangladesh, most of the participants' occupational and educational status were identified as housewife (57.9\%) and illiterate $(33.9 \%)$. These findings are different from the prior studies conducted in the same country. ${ }^{23}$ Differences in study methods and locations may be responsible for this difference.

Psychiatric patients cared for by participants were found to be suffering from schizophrenia, bipolar disorder, anxiety, psychosis, and depression. This finding upholds another study conducted in Bangladesh which implies that a mentally ill person in this country usually suffers from the above mentioned major mental illnesses. ${ }^{22}$ Thus, the training and awareness raising program focusing only on the mentioned disorders would be cost effective and time non-consuming and will be able to retain the caregiver on certain issues. On the other hand, the present study reveals some important information about hospitalization and medications of mentally ill persons, and activities of caregivers and care-recipients that will give other researchers some insight into conducting studies on this topic.

This study presents that most of the caregivers were experiencing moderate level of stress. No participants were found to be unstressed. This implies that the role of caregivers exerts pressure on caregivers. In regards to coping status, it is found that maximum participants had average levels of this condition. Although how caregivers approache for coping were not under investigation in this study; thus, research on coping strategies and its significance is recommended to carry out. In addition, stress reduction intervention may help to reduce stress and cope up with their conditions. The present study looked for a link separately between the socio-demographic status and stress or coping status. Except for income levels, none of the aspects of the socio-demography had found to be associated with the stress or coping status of caregivers. Since money plays a direct role in getting people access to various public and private services, there can be a direct relationship between income and stress or coping with it. Further study is recommended to understand in depth how income regulates the stress and coping position of caregivers.

In order to examine the psychological status and its relationship with coping styles among the caregivers of individuals with intellectual disability and psychiatric illness, Panicker and Ramesh (2019) conducted a study and found that use of positive reinterpretation and growth was associated with lower levels of depression and stress symptoms. ${ }^{24}$ The current study supports this finding as an association was found between the stresses and coping status among the caregivers. In addition, it is evident that caregivers with low stress do not seek enough coping style. Similarly, Kaur (2015) concluded that caregivers with low stress level had poor coping style. ${ }^{25}$ This study suggests the health professional to focus on the care giving situation to provide better support to them and also suggests that it shall be advisable to provide equivalent services for caregivers. Failure to find timely coping styles can lead to increased levels of stress later among caregivers which can ultimately have a detrimental effect on the proper care of mental patients.

\section{CONCLUSIONS}

In Bangladesh, major psychiatric conditions usually refer to schizophrenia, bipolar disorder, anxiety, psychosis, and depression. Person suffering from these conditions is labeled as a major psychiatric patient and the person who is cared for by these patients is regarded as a caregiver. In this country, parents play as the caregiver for most ill people. Caregivers of major psychiatric patients can experience low, moderate and high levels of stress because of their constant care giving role. On the other hand, poor, average and high coping conditions are found among the caregivers of mentally sick people. Except for income levels, none of the aspects of the socio-demography had found to be associated with the stress or coping status of caregivers. But caregivers stress and coping status are found 
to be interrelated. The Caregivers who experienced low stress showed poor coping status. Failure to plan and implement the proper intervention, services and program for the caregiver may negatively affect their care giving performance which can deteriorate the wellbeing of major psychiatric patients.

\section{REFERENCES}

1. Hossain MD, Ahmed HU, Chowdhury WA, Niessen LW, Alam DS. Mental disorders in Bangladesh: a systematic review. BMC Psychiatry 2014; 14(1):1-8.

2. Darlami K., Ponnose R ,Jose P. .Caregiver's stress of psychiatric patients. Journal of Universal College of Medical Sciences (2016); 3(2):39-43.

3. WHO (World Health Organization).Investing in mental health.Investing in mental health (2003): 3-49.

4. Nuri NN, Sarker M, Ahmed HU, Hossain MD, Beiersmann C, Jahn A. Pathways to care of patients with mental health problems in Bangladesh. Int J Ment Health Syst. (2018);12 (39):1-12.

5. Bugge C, Alexander H, Hagen S. Stroke patients informal caregivers. Patient,caregiver and service factor that affect caregiver. (2000); 30 (8): 15-23.

6. Pinquart M, Sörensen S. Differences between caregivers and non-caregivers in psychological health and physical health: A meta-analysis. Psychology and Aging. (2003);18 (2):250-67.

7. Mant J, Winner S, Roche J, Wade DT. Family support for stroke: one year follow up of a randomised controlled trial. J Neurol Neurosurg Psych. (2005);76 (7):1006-1008.

8. Derajew H ,Toless d, Feyissa G ,Addsu F, Sobaka M. Prevalence of depression and its associated factors among primary caregivers of patients with severe mental illness in southwest, Ethiopia. BMC Psychiatry. (2017); 17(1): $1-8$.

9. Harrison KL, Ritchie CS, Patel K, et al. Care Settings and Clinical Characteristics of Older Adults with Moderately Severe Dementia. J Am Geriatr Soc. (2019); 67(9):1907-1912.

10. Panicker AS, Ramesh S. Psychological status and coping styles of caregivers of individuals with intellectual disability and psychiatric illness. J Appl Res Intellect Disabil. (2019);32(1):1-14.

11. Vasileiou K, Barnett J, Barreto M, et al. Experiences of Loneliness Associated with Being an Informal Caregiver: A Qualitative Investigation. Front Psychol. (2017);8 (585):1-12.

12. Lazarus RS, Folkman S. Stress, Appraisal, and Coping.New York: Springer; 1984.
13. Scherer KR. Appraisal considered as a process of multi-level sequential checking. In: Scherer KR, Schorr A, Johnstone T, editors. Appraisal Processes in Emotion: Theory, Methods, Research. New York: Oxford University Press; 2001. p. 92-120.

14. Magliano L, Veltro F, Guarneri M, Marasco C. Clinical and socio-demographic correlates of coping strategies in relatives of schizophrenic patients. Eur Psychiatry (1995); 10 (2):155-8.

15. Magliano L, Fadden G, Fiorillo A, Malangone C, Sorrentino D, Robinson A, et al. Family burden and coping strategies in schizophrenia: Are key relatives really different to other relatives? Acta Psychiatr Scand (1999);99 (1):10-5.

16. Mueser KT, Valentiner DP, Agresta J. Coping with negative symptoms of schizophrenia: Patient and family perspectives. Schizophr Bull (1997);23(2):329-39.

17. Scazufca M, Kuipers E. Coping strategies in relatives of people with schizophrenia before and after psychiatric admission. Br J Psychiatry (1999); 174 (3):154-8.

18. Hassan WA, Mohamed II, Elnaser AE, Sayed NE. Burden and coping strategies in caregivers of schizophrenic patients. J Am Sci (2011);7(5):802-11.

19. Hoque MM . ABC of research methodology and bio-statistics, 3rd ed. Dhaka: Bangladesh medical book seller association; 2019.

20. Karim E,Alam M, Rhman AHM ,Hussain AAM ,Uddin $\mathrm{Mj}$,Firoz AHM. Prevalence of Mental Illness in the Community', TAJ. Journal of Teachers Association. (2011) ;19(1):18-23.

21. Ahmed A, Green BA, Clark CB, Stahl KC, Mcfarland M. Latent structure of unipolar and bipolar mood symptoms. Bipolar Disorders 2011; 13(5-6):522-36.

22. Sunita Mahtani Stewart, Michael Harris Bond, Abu Saleh M. Abdullah and Stefan S. L. Gender, Parenting, and Adolescent functioning in Bangladesh. Ma Merrill-Palmer Quarterly (2000); 46 (3): 540-64.

23. Firoz AHM, Karim MDE, Alam MF, Rahman AHMM, Zaman MM, Rabbani MG. Awareness, Care and Acceptance of Mental Patients: A Nationwide Multicentric Community Survey in Bangladesh. Journal of NIMH. (2009);1(1):9-30.

24. Panicker AS, Ramesh S. Psychological status and coping styles of caregivers of individuals with intellectual disability and psychiatric illness. Journal of Applied Research in Intellectual Disabilities 2018; 32(1): 1-14 .

25. Kaur S, Kiran UV. Stress among parents and caregivers of differently abled children.Journal for Studies in Management and Planning. (2015);1(7):172-184. 